\title{
Negative evidence regarding energization effects of simple, unchanging stimulation
}

\author{
GORDON N. CANTOR and THOMAS G. MOELLER* \\ Institute of Child Behavior and Development \\ University of Iowa, Iowa City, Iowa 52240
}

Seventh- and eighth-grade boys viewed picture exposures that alternated with a lever-pulling response. Group SUN (simple, unchanging, nonmeaningful) viewed 1260 -sec presentations of a constant simple geometric form. Group CCM (complex, changing, meaningful) viewed 6 10-sec exposures of nonrepeated meaningful pictures on each of 12 trials. Group SUN responded with nonsignificantly smaller amplitudes, with nonsignificantly longer latencies, and with significantly longer durations. It was concluded that no clear evidence was obtained for energization effects of simple unchanging stimulation. The duration finding was interpreted as indicating that Group SUN Ss were responding so as to provide themselves with additional (kinesthetic) stimulation.

In his adaptation of Spence's (1956) formulation regarding instrumental appetitive conditioning, Fowler (1967) has postulated that exposure to an unchanging stimulus surround leads to a heightened state of drive (D) in the organism. If this assumption is valid, an application of Hull-Spence theory suggests that one should be able to demonstrate an energization effect resulting from such exposure. Following Fowler, one would expect greater energization effects the longer the duration of stimulation and the greater its homogeneity. Fowler (1967) presents evidence in support of his position stemming from studies concerned with runway behavior in rats.

The present paper reports the fourth in a series of experiments designed to test Fowler's drive theory, using children as Ss. The three earlier studies (Cantor, 1968; Fenson, 1968; Kubose, 1969), although differing in many respects, all entailed use of a basic paradigm calling for exposures of children to visual stimulation considered to differ in degree of heterogeneity and meaningfulness. Such exposures were alternated with motor responding for which speed measures were obtained. In terms of statistically significant effects, only the Kubose (1969) study produced results consistent with Fowler's drive theory, Kubose's Ss responding faster following 18-sec than following 8-sec stimulus presentations. But Kubose failed to find consistent differential responding following stimulation varying in heterogeneity, and Cantor (1968) and

\footnotetext{
*We are indebted to Merle W. Miller and Yossef Geshuri for their invaluable help in designing and constructing the apparatus used in this experiment. Thanks are also due to Norbert Meyer (Principal) and his colleagues at the Iowa City Central Junior High School for their cooperation.
}

Fenson (1968) obtained evidence indicating an association between simple stimulation and relatively slow motor responding.

The present study differed from the earlier ones by virtue of the inclusion of an amplitude and duration as well as a speed measure. The Ss were older than those previously employed, and an attempt was made to select stimuli for presentation to one of the groups (Group CCM) that would have more interest value for the Ss in question than previously was the case.

\section{SUBJECTS, APPARATUS, AND STIMULI}

The Ss were 46 seventh- and eighth-grade boys residing in the Iowa City area. They were paid $\$ 1.50$ for participating. Twenty-three Ss (mean CA = 13 years, 0 months) were assigned to Group SUN (simple, unchanging, nonmeaningful stimulation), the remaining 23 Ss (mean $\mathrm{CA}=13$ years, 3 months) being assigned to Group CCM (complex, changing, meaningful stimulation).

The motor-task apparatus consisted essentially of a joy-stick arrangement. The S sat on a swivel chair, his legs extending on either side of a vertical lever. The lever a solid 3/4-in. steel rod, was tilted slightly forward in its resting position. A wooden box with a slot cut in its top housed the base of the lever and an adjustable heavy-duty spring system that exerted tension on the lever when $S$ pulled it toward him. A Bourns potentiometer was attached to the base of the lever. Wooden blocks fastened to either side of the box provided footrests for S. Additional pieces of equipment included a 1/8-in. ground-glass screen $(25 \times 25$ in.), a Carousel RA950 slide projector, an Offner Dynograph amplifier-recorder (Type 542), two Hunter interval timers (used to control stimulus exposure durations and anticipation intervals), and a solenoid-activated Nutone door chime (the CS for the motor response).

A total of $7935-\mathrm{mm}$ slides was employed. One slide, all black, was used during anticipation intervals. A second slide, a practice stimulus for Group SUN, consisted of a black cross outlined in white on a black background. A third slide, a white $\mathrm{X}$ with a white dot located within each of its four angles and a black background, served as the simple unchanging nonmeaningful stimulus for Group SUN. The remaining 76 slides (four for practice) were used for Group CCM. The pictures on which these slides were based, some black and white and others in color, were taken from a variety of sports and entertainment magazines. Fifty-six of the pictures were action shots of sports scenes (basketball, football, baseball, hockey, skiiing, hunting, and fishing). The remaining 20 were pictures of familiar individuals or groups appearing in current TV programs.

\section{PROCEDURE}

All Ss were run individually in a dimly illuminated laboratory room. The $\mathrm{S}$ was first given two chances to pull the lever back and allow it to return to its starting position. Any questions asked regarding amplitude or duration of the pull were responded to by $\mathrm{E}$ in a nondirective fashion.

The instructions subsequently given to Ss in Groups SUN and CCM were identical, except for differences dictated by the fact that Group SUN Ss were to view a single stimulus, whereas Group CCM Ss were to view changing nonrepeated stimuli. The $S$ was told he would see pictures on the screen, and he was to watch them carefully, keeping his hands in his lap. He was told that when "the picture" (Group SUN) or "the last picture" (Group CCM) went off, E would say, "Grasp the handle"-S's signal to place both hands on the lever. The $\mathrm{S}$ was told a bell would then sound, this being the signal to pull the lever and then allow it to return to its resting position.

Two practice trials were then given, using the cross as the stimulus for Group SUN and 4 of the 76 meaningful pictures as the stimuli for Group CCM. In the case of Group SUN, the cross was projected for a 10-sec interval on these trials; for Group CCM two of the four pictures were projected on each trial, the exposure duration per picture being 5 sec. The $S$ responded each time to the CS by pulling the lever, as instructed.

Twelve test trials were then administered. For Group SUN these 


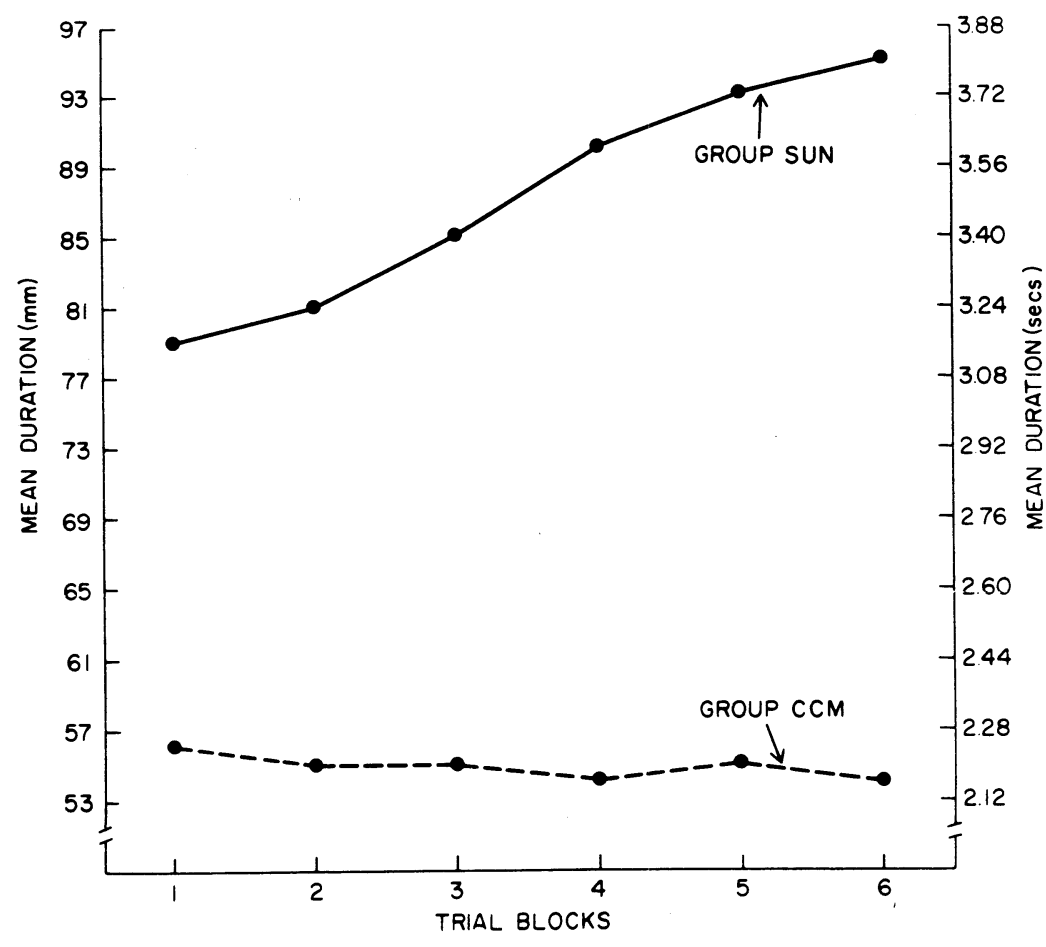

Fig. 1. Duration means across trial blocks for Group SUN and Group CCM.

entailed 60 -sec exposures of the geometric form ( $\mathrm{X}$ with dots). Concurrent with visual stimulus offset, the verbal ready signal ("Grasp the handle") was given. Anticipation intervals (time between ready signal and CS) were 3 and $4 \mathrm{sec}$, these being randomly distributed across trials, with the restriction that they occur equally often within 4-trial blocks. The CS and S's lever response then followed. For Group CCM the test trial procedures were identical to those just described, except for the fact that successive 10-sec presentations of six different meaningful pictures occurred during the 60-sec exposure interval, these never being repeated within or across trials. The ready signal in this case was given concurrently with the offset of the sixth picture in the series on a given trial. To avoid confounding any possible trial blocks effect with a particular sequence of visual stimuli given to Group CCM, 12 different stimulus orders were constructed, with two Group CCM Ss being assigned to each of 11 of the orders and the 12th order being used for the remaining $S$ in that group.

In order to preclude S's viewing a given lever pull as being instrumental with regard to the subsequent visual stimulus presentation, he was asked to engage in a simple letter cancellation task between test trials. The ITI averaged about $20 \mathrm{sec}$ in duration.

An event marker on the polygraph was used to record CS onset for the motor task. A second pen served to record S's lever-pulling responses. A circuit connecting the lever, the potentiometer, and the polygraph produced pen deflections used to obtain the following dependent measures: (1) response latency (distance from CS onset to initial deviation of the pen from baseline), (2) maximum deflection (amplitude) (distance from baseline to the largest deflection occurring on the trial in question), and (3) response duration (distance from initial deviation from baseline to return to baseline). Paper speed was $25 \mathrm{~mm} / \mathrm{sec}$ for all Ss.

\section{DESIGN AND PREDICTIONS}

A mixed analysis of variance design was used, with groups (SUN vs CCM) as a between-Ss variable and trial blocks (six blocks of two trials each) as a within-Ss variable. The only clear prediction that could be made pertained to the maximum deflection measure, the expectation being that Group SUN would produce larger amplitudes than would Group CCM, with the magnitude of the difference increasing across trial blocks. Such a pattern would be consistent with the assumption that Group SUN Ss would be characterized by a higher level of $\mathrm{D}$ than would those in Group CCM, a cumulative effect making the difference increasingly apparent across trials.

Hullian theory did not permit a straightforward prediction regarding response latency. Since this is a measure peculiarly sensitive to interference effects (Spence, 1956; Rabinowitz, 1966), one could expect Group SUN to respond less promptly than Group CCM if drive-stimulus-produced competing responses were playing a role in the situation, but more promptly if response competition were not involved. Hullian theory does not include response duration as a dependent variable in the system. However, it was assumed that Group SUN performance characterized by long durations coupled with high-amplitude responding would strongly support the postulation of an energization effect attributable to simple unchanging nonmeaningful stimulation. RESULTS AND DISCUSSION

The overall maximum deflection means were $15.33 \mathrm{~mm}$ for Group SUN and $16.00 \mathrm{~mm}$ for Group CCM. None of the effects in the maximum deflection analysis was significant and, contrary to expectation, Group CCM means consistently exceeded those for Group SUN across trial blocks.

The overall latency mean for Group SUN was $16.92 \mathrm{~mm}$ (677 msec), whereas that for Group CCM was $15.18 \mathrm{~mm}$ (607 $\mathrm{msec})$. Group SUN's responding was consistently slower than that of Group CCM across trial blocks. The only significant effect in the analysis of variance, however, was that for trial blocks $(F=2.66, \quad d f=5 / 220, \quad p<.05), \quad$ the responses of both groups decreasing in promptness across trial blocks.

The overall duration means were $87.15 \mathrm{~mm}(3.49 \mathrm{sec})$ for Group SUN and $54.85 \mathrm{~mm}(2.19 \mathrm{sec})$ for Group CCM. The trial block means for both groups may be seen in Fig. 1. The groups effect was in this case significant $(F=5.49, \quad \mathrm{df}=1 / 44$, $\mathrm{p}<.05)$, with Group SUN consistently exceeding Group CCM in duration across trial blocks. Neither of the remaining effects was significant.

In view of the sizable discrepancy between Groups SUN and CCM in duration variances $(S D=60.13 \mathrm{~mm}$ for Group $S U N$, $\mathrm{SD}=27.52 \mathrm{~mm}$ for Group CCM), these data were also subjected to a Mann-Whitney U test using as each S's score his overall duration mean. The resulting value of $z(-2.03)$ is significant at the .05 level (two-tailed).

The results provide no clear support for the contention that repetitive exposure to a simple nonmeaningful visual stimulus serves as an energizer of behavior. Though small and statistically nonsignificant, the maximum deflection differences (considered crucial for the hypothesis under investigation) consistently favored Group CCM across all trial blocks, 
suggesting, if anything, the presence of a low level of D in Group SUN. The nonsignificantly slower latencies for Group SUN across all trial blocks could be viewed as being consistent with such an interpretation. The significant trial blocks effect in the latency analysis, together with the nonsignificant Groups by Trial Blocks interaction, indicates that both groups were becoming less attentive across trials.

Finally, the significant main effect for groups in the duration analysis, considered in conjunction with the other findings, suggests that the Ss in Group SUN were making relatively prolonged responses as a means of providing themselves with additional stimulation (presumably kinesthetic in nature). Note that the duration function for Group CCM is a flat one, whereas that for Group SUN increases monotonically across trial blocks, suggesting a Groups by Trial Blocks interaction (see Fig. 1). The failure to obtain a significant interaction in the analysis of variance was doubtless due to the extreme variability of the duration data.

While it is tempting to consider the possibility that the groups effect in the duration data signifies greater energization for Group SUN, the amplitude results are clearly not consistent with such a view. One might wish to argue that the meaningful pictures selected for presentation to Group CCM did not have the "interest value" they were assumed to have for those Ss, and thus, in a functional sense, Groups SUN and CCM were not treated differently. It would not seem, however, that such a position could be easily reconciled with the significant groups main effect in the duration data and the consistency in the direction of differences across all trial blocks in the amplitude and latency data.

Taking the present results in conjunction with those of earlier studies in the series, one must conclude we have been singularly unsuccessful in demonstrating the energization effect predicted by Fowler's theory. Perhaps the theory does not apply to children's behavior. Alternatively, perhaps the experimental manipulations we have employed have not been sufficiently powerful and/or our dependent measures have been inappropriately selected. Still another possibility is that the theory is wrong and that repetitious, simple stimulation actually leads to a low level of D (see especially Cantor, 1968, and Fenson, 1968, for evidence consistent with the latter view).

\section{REFERENCES}

CANTOR, G. N. Effects of a "boredom" treatment on children's simple RT performance. Psychonomic Science, 1968, 10, 299-300.
IENSON, L. Effects of two types of repetitive and nonrepetitive stimulation on children's response speeds. Unpublished doctoral dissertation, University of Iowa, 1968.

FOWLER, H. Satiation and curiosity: Constructs for a drive and incentive-motivational theory of exploration. In K. W. Spence and J. T. Spence (Eds.), The psychology of learning and motivation. Vol. 1. New York: Academic Press, 1967. Pp. 157-227.

KUBOSE, S. K. Effects of type and duration of visual stimulation on children's motor task response speeds. Unpublished doctoral dissertation, University of Iowa, 1969.

RABINOWITZ, F. M. Conditioned stimulus duration and delay of reward as variables in a lever pulling situation. Journal of Experimental Child Psychology, 1966, 3, 225-234

SPENCE, K. W. Behavior theory and conditioning. New Haven: Yale University Press, 1956.

\title{
Disruption of short-term memory in man following consumption of ethanol*
}

\author{
RALPH S. RYBACK $\dagger$ \\ Boston City Hospital and Harvard Medical School, Boston, Mass. 02115 \\ and \\ JANE WEINERT and JAMES L. FOZARD \\ Psychiatry Research Department, Massachusetts General Hospital, Boston, Mass. 02114
}

Over a 45-min period, accuracy of recognition of previously presented pictures systematically decreased in 10 nonalcoholics after a moderate amount of alcohol was consumed. The decline in performance was relatively greater when the number of pictures between the old picture and its question was larger, suggesting that alcohol affected retrieval as well as attention mechanisms.

In terms of threefold classification of memory function (Shuttleworth \& Morris, 1966), alcohol amnesia seems to be a type of short-term or intermediate-level memory deficit, usually associated with a prolonged acute or relatively acute rise in the blood alcohol concentration. There is less difficulty with immediate or with long-term or remote memory (Ryback, 1969, 1970a, b). The present study investigated the effects of alcohol on short-term memory in one task (Fozard \& Yntema, 1966) in which performance does not appear to depend importantly on an individual's proficiency or adaptability to it (Carpenter \& Ross, 1963).

\section{MATERIALS AND METHODS}

Ss inspected a long sequence of single colored pictures of animals, food, implements, persons, plants, or other objects. They were drawn from a set of 1,600 ; some were copies of those used by Shepard (1967). After every two inspection pictures, a question containing two pictures was presented. In some questions one of the two pictures had been presented earlier in the experiment and the other had not; the S's task was to select the previously presented picture, i.e., recognize the "old" picture. After its presentation in

*Paper presented at the AAAS, Boston, Massachusetts, Dec. 29, 1969. Supported in part by National Science Foundation Grant GB7837 to the Massachusetts General Hospital and V.A. Outpatient Clinic and in part by NIMH Grant No. 09245 to the Alcohol Study Unit, Boston City Hospital.

† Present address: McLean Hospital, Belmont, Mass. 02178. a question, a picture was not shown to the $S$ again. In other questions both pictures had been presented earlier in the experiment, and the $\mathrm{S}$ selected the picture he believed had been presented more recently. Only the data from the first of the two tasks are described here.

The number of items separating the initial presentation of a picture from its question took on one of four average values. The smallest separation was 24 or 25 items (24.5). The others were 48.5 , 96.5 , and 192.5 items. This count included items in earlier questions as well as new items. Sequences of stimuli and questions were photographed on $16-\mathrm{mm}$ color film and presented to each $S$ by means of a movie projector adapted for single frame advance. The experiment was entirely S-paced.

The Ss were five male and nine female undergraduates and medical students, 21-29 years of age. The 10 experimental Ss received $1.2 \mathrm{cc} / \mathrm{kg}$ of body weight of $95 \%$ ethanol diluted with $300 \mathrm{ml}$ of orange juice, which they consumed with in $30 \mathrm{~min}$. The four control Ss received an equal volume of orange juice but with $1 \mathrm{cc}$ of $95 \%$ ethanol. Ss were not told whether they were in the experimental or control group, and all had not eaten for at least $4 \mathrm{~h}$.

At the beginning of the experiment, all Ss received practice trials followed by test trials to establish a base level of performance. After the drinking period, Ss resumed the experiment. After 30 and $45 \mathrm{~min}$ of testing, their blood alcohol level was determined by a breathalyzer. ${ }^{1}$ The 